\title{
Physical Wellbeing in Cervical and Breast Cancer Survivors: A Cross-sectional Study in Surabaya, Indonesia
}

Ni Putu Wulan Purnama Sari

Department of Palliative Nursing, Faculty of Nursing,Widya Mandala Catholic University Surabaya, Indonesia

\begin{tabular}{l} 
A R T I C L E I N F O \\
\hline Article history: \\
Received : 18 October 2018 \\
Reviewed: 05 November 2018 \\
Accepted : 19 November 2018
\end{tabular}

Keywords:

Breast cancer, Cervical cancer, Physical wellbeing.
*Corresponding author:

Ni Putu Wulan Purnama Sari Department of Palliative Nursing, Faculty of Nursing, Widya Mandala Catholic University, Surabaya Email:

wulanpurnama@ukwms.ac.id

\begin{abstract}
A B STR A CT
Background: Cervical and breast cancer are the two top leading cases of female cancer worldwide. Both cases share some similar clinical manifestations as specific symptoms of cancer. Physical wellbeing often decreased as frequent symptoms appear. This study aimed to compare and analyze the physical wellbeing among cervical cancer and breast cancer survivors (CCS and BCS).
\end{abstract}

Methods: This cross-sectional study involved 47 CCS and 58 BCS in the district of Rangkah, Gading, and Pacarkeling, Surabaya, Indonesia. Instrument of Quality of Life Cancer Survivors (QOL-CS) was used for data collection. Independent sample T test and Mann-Whitney $U$ test were used in data analysis $(\alpha<.05)$.

Results: More severe fatigue, appetite changes, pain, sleep disturbance, constipation, nausea-vomiting, and menstrual changes were found in CCS. More poor perceived health status and optimal physical wellbeing were found in BCS. Overall, most sufficient physical wellbeing was found in both groups. There were significant differences of fatigue, pain, sleep disturbance, appetite changes, constipation, health status $(p<.001$ for each), nausea-vomiting $(p=.004)$, and menstrual changes $(p=.001)$ were found between groups. Overall, physical wellbeing was significantly different between groups $(p<.001)$. Sleep disturbance ( $84.7 \%$ of influence) and appetite changes $(75.7 \%$ of influence) were the best predictors for determining physical wellbeing in CCS and BCS respectively.

Conclusion: More severe cancer symptoms were found in CCS, but more poor perceived health status was found in BCS. There was a significant difference of physical wellbeing found between CCS and BCS.

\section{INTRODUCTION}

Cancer is the growth of new cells that form abnormal tissue and characterized by uncontrolled function (1). It can be estimated that the incidence of cancer in Indonesia is $0.1 \%$ of the population, and more than $50 \%$ of cancer patients firstly come to seek for medication in an advanced stage. According to World Health Organization (WHO) statistics, cancer is the highest cause of death in the world; up to 7.6 million deaths (13\% of all deaths) in 2008. In the same year, Indonesia's death rate from cancer was 245 per-100,000 inhabitants (men > women) in which lung cancer being the most frequent killer, followed by breast and colon cancer. In 2014, breast cancer occupies the first position of leading cause of death, followed by cervical cancer with the number of 20.928 cases in Indonesian women (2). In the period of six years we can see that more women suffered from cancer. Cervical and breast cancer have been the two top leading cases of female cancer in Indonesia for several years until now.

The pain/suffering experienced by cancer patients is total pain/suffering which consists of physical, psychological, social, and spiritual problems (3). All of these problems are rooted from the level of cancer symptoms or clinical manifestation. In the case of advanced cancer (stages 3 and 4), this total pain/suffering will further adversely affect the physical wellbeing and health status along with the disease progression. Physical wellbeing is a state of the ability to be fully engaged on a regular basis including its development (4). In the case of cancer, there are eight indicators of physical wellbeing which are being a part of quality of life domains in cancer survivors, namely: fatigue, appetite changes, pain, sleep disturbance, constipation, nausea-vomiting, menstrual changes, and health status (perceived) (5). Patients with multiple and severe cancer symptoms had worse performance status, 
role functioning; physical, emotional, cognitive, social, and overall health-related quality of life (HRQOL) (6). Therefore, physical wellbeing often decreased as frequent cancer symptoms appear. This study aimed to compare and analyze the physical wellbeing among cervical cancer survivors (CCS) and breast cancer survivors (BCS). By knowing this study results, physicians and nurses in the field could stress their interventions towards specific cancer symptoms which significantly impact the physical wellbeing of CCS and BCS as this variable being one of the domain of HRQOL.

\section{METHODS}

This cross-sectional study involved 47 CCS and 58 BCS in the district of Rangkah, Gading, and Pacarkeling, Surabaya, Indonesia. Inclusion criteria were being an adult ( $>18$ years old), with cancer diagnosis that has been confirmed, and regularly home-visited by a palliative volunteer under the supervision of Rangkah Public Health Center, Surabaya. Exclusion criteria were rejection on filling out the consent form, very poor condition, and consciousness loss or disorientation. Total sampling was applied and sample size of 105 was obtained. Instrument of QOL-CS developed by Ferrel, et al. (1995) was used in data collection process (5). Data were collected since February until March, 2018. Independent sample $T$ test and Mann-Whitney $U$ test were used in data analysis $(\alpha<.05)$. Ethical clearance was issued by Faculty of Nursing, Universitas Airlangga, Surabaya, Indonesia, with certificate number of 681KEPK.

\section{RESULTS}

Most respondents were Javanese, Islam, married, housewife, with Gross Domestic Product (GDP) less than the minimum wage of Surabaya in 2018 (IDR $3,300,000.00)$. Educational background, occupational status, and GDP were better in the group of BCS. CCS were mostly aged 51-60 years old with tendency to elderly, but BCS were mostly aged $41-60$ years old with tendency to younger age. These results indicate that the majority of female cancers suffered by late adult women were occured among lower-middle socioeconomic status. CCS who was married mostly had no child, but most BCS live with their spouse and children. More single women were found to have breast cancer in this study. Table 1 shows the demography characteristic of study respondents in details.

In this study context, more cases of breast cancer were found compared to cervical cancer cases (more than 50\%). This result further confirmed that breast cancer was still being the top leading cases of female cancer in Indonesia since 2014. Until now, breast and cervical cancer are still being the two top leading cases of female cancer in Indonesia.

The majority of respondents in both groups were diagnosed before 2014 (more than four years before this study was conducted). This indicates that the survival rate of breast and cervical cancer is particularly long, which makes both types of cancer a chronic disease with high burden that requires long-term and supportive/palliative care. Most BCS undertook surgery only, both for curative and palliative purposes. In the other hand, most CCS undertook a more complex regiment, which is a modification of surgery and chemoradiotherapy. There were $1.9 \%$ of total respondents prefer not to undergo any therapy. Regardless of minimum information, lack of knowledge, financial problems, or personal beliefs/preference, these 1.9\% respondents expressed good condition despite of not getting any therapy.

Data of fatigue, pain, sleep disturbance, and overall physical wellbeing were normally distributed $(p=.231, p$ $=157, p=.063$, and $p=.484$ respectively), therefore the independent sample $\mathrm{T}$ test was used for analyzing the data. In the other hand, data of appetite changes, constipation, nausea-vomiting, menstrual changes, and health status were not normally distributed $(p>\alpha)$, therefore Mann-Whitney $U$ test was used for analyzing the data. There were significant differences of fatigue, pain, sleep disturbance, appetite changes, constipation, health status ( $p<.001$ for each), nausea-vomiting ( $p=$ $004)$, and menstrual changes ( $p=.001$ ) found between CCS and BCS. Overall, physical wellbeing was significantly different between CCS and BCS $(p<.001)$. Table 3 explains the differences of every aspect of physical wellbeing in both groups.

We found more severe fatigue, appetite changes, pain, sleep disturbance, constipation, nausea-vomiting, and menstrual changes in CCS. Surprisingly, they expressed better health status than BCS. Even so, physical wellbeing was better in BCS. This may be influence by various factors involving disease mechanism, host response towards tumor/cancer, and side effect of anti-cancer therapy. Physical wellbeing as defined by Ferrel et al. (1995) is the summary of fatigue, appetite changes, pain, sleep disturbance, constipation, nausea-vomiting, menstrual changes, and health status (perceived) (5). We tried to determine which one of all these aspects being the best predictor or major determinant of physical wellbeing in CCS and BCS. Simple linear regression test was used for analyzing the data.

Sleep disturbance is the best predictor of physical wellbeing in CCS followed by pain, nausea-vomiting, appetite changes, fatigue, constipation, menstrual changes, and health status. Sleep necessity needs to be addressed optimally in CCS together with good pain management because pain is highly potential to be the cause of sleep problems. 
Table 1. Demography characteristics

\begin{tabular}{|c|c|c|c|c|c|}
\hline \multirow{2}{*}{\multicolumn{2}{|c|}{ Characteristics }} & \multicolumn{2}{|c|}{$\begin{array}{c}\text { Cervical cancer } \\
(n=47)\end{array}$} & \multicolumn{2}{|c|}{$\begin{array}{c}\text { Breast cancer } \\
(n=58)\end{array}$} \\
\hline & & Frequency & $\%$ & Frequency & $\%$ \\
\hline \multicolumn{6}{|c|}{ 1. Age (years old) } \\
\hline & a. $<21$ & 0 & 0 & 1 & 1.7 \\
\hline & b. $21-30$ & 0 & 0 & 5 & 8.6 \\
\hline & c. $\quad 31-40$ & 5 & 10.6 & 10 & 17.2 \\
\hline & d. $41-50$ & 11 & 23.4 & 15 & 25.8 \\
\hline & e. $51-60$ & 17 & 36.1 & 15 & 25.8 \\
\hline & f. $\quad 61-70$ & 13 & 27.6 & 8 & 13.7 \\
\hline & g. $>70$ & 1 & 2.1 & 4 & 6.9 \\
\hline \multicolumn{6}{|c|}{ 2. Religion } \\
\hline & a. Catholic & 0 & 0 & 1 & 1.7 \\
\hline & b. Christian & 7 & 14.8 & 11 & 18.9 \\
\hline & c. Islam & 40 & 85.1 & 46 & 79.3 \\
\hline \multicolumn{6}{|c|}{ 3. Ethnic } \\
\hline & a. Javanese & 40 & 85.1 & 57 & 98.2 \\
\hline & b. Maduranese & 6 & 12.7 & 0 & 0 \\
\hline & c. Chinese & 1 & 2.1 & 1 & 1.7 \\
\hline \multicolumn{6}{|c|}{ 4. Educational background } \\
\hline & a. Primary school & 15 & 31.9 & 11 & 18.9 \\
\hline & b. Secondary school & 14 & 29.7 & 5 & 8.6 \\
\hline & c. High school & 13 & 27.6 & 26 & 44.8 \\
\hline & d. Diploma / Bachelor degree & 2 & 4.2 & 15 & 25.8 \\
\hline & e. Uneducated & 3 & 6.3 & 1 & 1.7 \\
\hline \multicolumn{6}{|c|}{ 5. Marital status } \\
\hline & a. Single & 3 & 6.3 & 8 & 13.7 \\
\hline & b. Married & 39 & 82.9 & 36 & 62.0 \\
\hline & c. Widow & 4 & 8.5 & 14 & 24.1 \\
\hline & d. Divorce & 1 & 2.1 & 0 & 0 \\
\hline \multicolumn{6}{|c|}{ 6. Living at home with } \\
\hline & a. Spouse & 39 & 82.9 & 30 & 51.7 \\
\hline & b. Children & 17 & 36.1 & 35 & 60.3 \\
\hline & c. Alone & 3 & 6.3 & 2 & 3.4 \\
\hline & d. Parents & 0 & 0 & 11 & 18.9 \\
\hline & e. Sibling & 0 & 0 & 2 & 3.4 \\
\hline \multicolumn{6}{|c|}{ 7. Occupational status } \\
\hline & a. Full-timer & 2 & 4.2 & 11 & 18.9 \\
\hline & b. Part-timer & 3 & 6.3 & 2 & 3.4 \\
\hline & c. Retired & 0 & 0 & 4 & 6.9 \\
\hline & d. Housewife & 40 & 85.1 & 37 & 63.7 \\
\hline & e. Seeking for a job & 0 & 0 & 1 & 1.7 \\
\hline & f. Unemployed & 2 & 4.2 & 3 & 5.1 \\
\hline \multicolumn{6}{|c|}{ 8. GDP per month } \\
\hline & a. Less than minimum wage & 34 & 72.3 & 34 & 58.6 \\
\hline & b. Minimum wage - IDR 5 million & 8 & 17.0 & 14 & 24.1 \\
\hline & c. More than IDR 5 million & 3 & 6.3 & 6 & 10.3 \\
\hline & d. No income & 2 & 4.2 & 3 & 5.1 \\
\hline
\end{tabular}


Appetite changes is being the best predictor for determining physical wellbeing in BCS, followed by fatigue, nausea-vomiting, constipation, pain, sleep disturbance, menstrual changes, and health status. Appetite changes could cause nutritional problem, therefore clinicians should give more attention to appetite changes in BCS.

\section{DISCUSSION}

Results showed that there were significant differences of fatigue, pain, sleep disturbance, appetite changes, constipation, health status ( $p<.001$ for each), nausea-vomiting $(p=.004)$, and menstrual changes $(p=$ .001) found between CCS and BCS. Overall, physical wellbeing was significantly different between CCS and BCS $(p<.001)$. Sleep disturbance and appetite changes are the best predictor of physical wellbeing in CCS and BCS respectively ( $p<.001$ for each)

Cancer-related fatigue (CRF) is a highly prevalent and debilitating symptom experienced by most cancer patients during, and often for considerable periods after, treatment. The negative impact of CRF could be experienced even before the formal diagnosis of cancer was established, and continually existed in the process of therapy (7). This CRF was found to be significantly different in CCS and BCS. Table 3 showed that most respondents of both cases experienced moderate fatigue, but more severe fatigue was found in CCS. This possibly caused by the complexity of therapeutic regiment followed by CCS as shown in Table 2: mostly surgery + chemotherapy + radiotherapy (36.17\%), compared to most surgery only in BCS (44.83\%).

Table 2: Primary data

\begin{tabular}{|c|c|c|c|c|c|}
\hline \multirow{2}{*}{\multicolumn{2}{|c|}{ Characteristics }} & \multicolumn{2}{|c|}{ Cervical cancer $(n=47)$} & \multicolumn{2}{|c|}{ Breast cancer $(n=58)$} \\
\hline & & Frequency & $\%$ & Frequency & $\%$ \\
\hline \multicolumn{6}{|c|}{ 1. Firstly diagnosed } \\
\hline a. & 2018 & 0 & 0 & 4 & 6.9 \\
\hline b. & 2017 & 7 & 14.8 & 16 & 27.5 \\
\hline c. & 2016 & 12 & 25.5 & 7 & 12.0 \\
\hline d. & 2015 & 5 & 8.6 & 10 & 17.2 \\
\hline e. & 2014 & 5 & 8.6 & 3 & 5.1 \\
\hline f. & $<2014$ & 18 & 38.3 & 18 & 31.0 \\
\hline \multicolumn{6}{|c|}{ 2. Type of therapy } \\
\hline a. & Surgery & 5 & 8.6 & 26 & 44.8 \\
\hline b. & Chemotherapy & 13 & 27.6 & 8 & 13.7 \\
\hline c. & Surgery + chemotherapy & 2 & 4.2 & 11 & 18.9 \\
\hline d. & Surgery + radiotherapy & 0 & 0 & 1 & 1.7 \\
\hline e. & Chemotherapy + radiotherapy & 7 & 14.8 & 1 & 1.7 \\
\hline f. & Surgery + chemotherapy + radiotherapy & 17 & 36.1 & 5 & 8.6 \\
\hline g. & Surgery + chemotherapy + radiotherapy + analgesic & 1 & 2.1 & 0 & 0 \\
\hline h. & Surgery + chemotherapy + radiotherapy + medicine & 1 & 2.1 & 0 & 0 \\
\hline i. & Surgery + chemotherapy + oral medicine & 0 & 0 & 1 & 1.7 \\
\hline j. & Oral medicine (various types) & 0 & 0 & 4 & 6.9 \\
\hline k. & Untreated & 1 & 2.1 & 1 & 1.7 \\
\hline
\end{tabular}

Table 3: Physical wellbeing in CCS and BCS

\begin{tabular}{|c|c|c|c|c|c|}
\hline \multirow{2}{*}{\multicolumn{2}{|c|}{ Characteristics }} & \multicolumn{2}{|c|}{ Cervical cancer $(n=47)$} & \multicolumn{2}{|c|}{ Breast cancer $(n=58)$} \\
\hline & & Frequency & $\%$ & Frequency & $\%$ \\
\hline \multicolumn{6}{|c|}{ 1. Fatigue } \\
\hline & a. Severe & 19 & 40.4 & 10 & 17.2 \\
\hline & b. Moderate & 23 & 48.9 & 21 & 36.2 \\
\hline & c. Mild & 5 & 10.6 & 7 & 12.0 \\
\hline \multicolumn{6}{|c|}{ 2. Appetite changes } \\
\hline & a. Severe & 18 & 38.3 & 6 & 10.3 \\
\hline & b. Moderate & 17 & 36.1 & 11 & 18.9 \\
\hline & c. Mild & 12 & 25.5 & 41 & 70.6 \\
\hline \multicolumn{6}{|c|}{ 3. Pain } \\
\hline & a. Severe & 14 & 29.7 & 5 & 8.6 \\
\hline
\end{tabular}




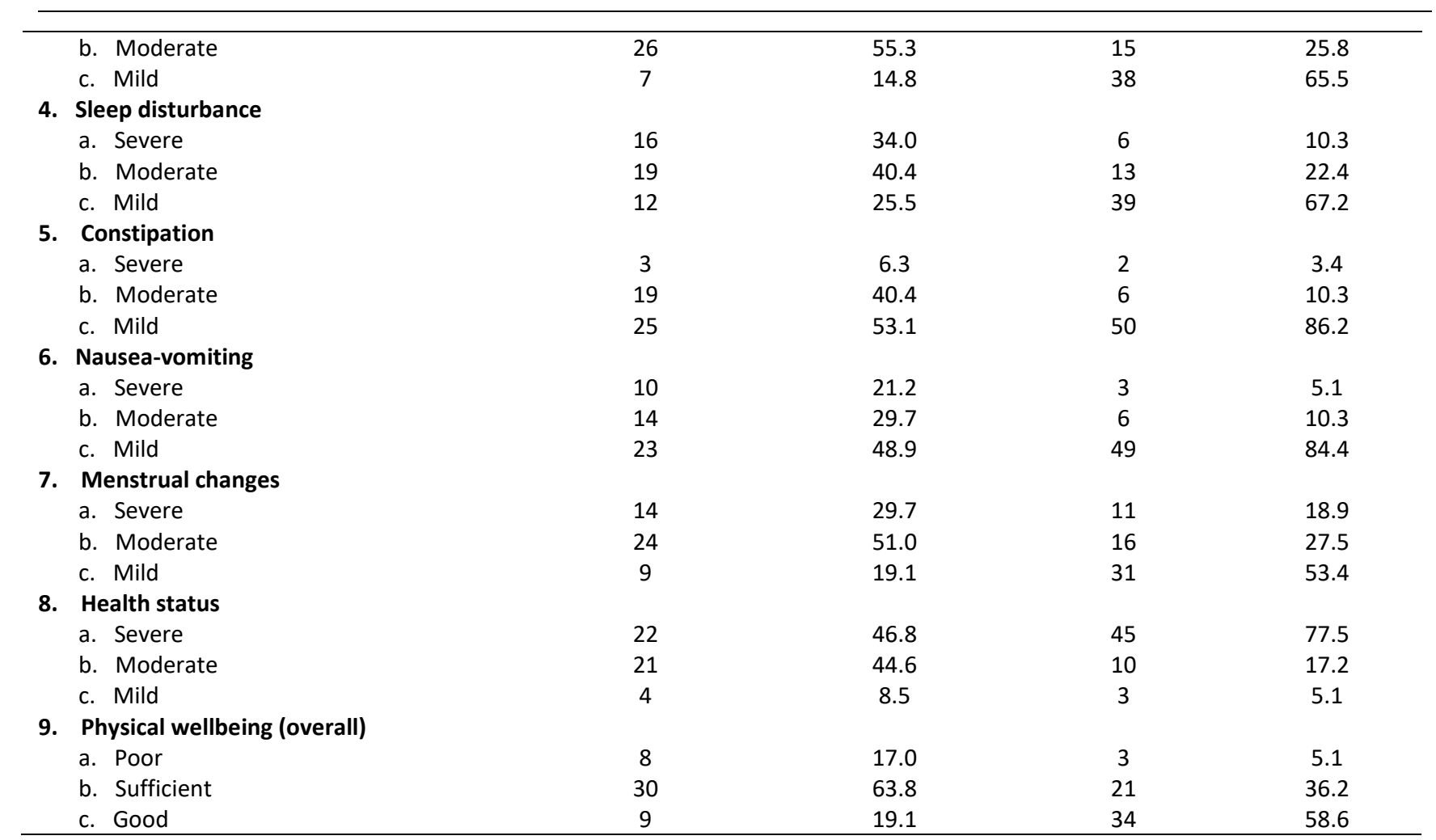

${ }^{*}$ Category was made to ease the data presentation only, and not for statistical analysis purposes

Table 4a: Predictors of physical wellbeing in CCS

\begin{tabular}{|c|c|c|c|c|}
\hline No. & Determinant & R Square & $\%$ OF Influence & Sig. \\
\hline 1 & Fatigue & .611 & 61.1 & .000 \\
\hline 2 & Appetite changes & .659 & 65.9 & .000 \\
\hline 3 & Pain & .751 & 75.1 & .000 \\
\hline 4 & Sleep disturbance & .847 & 84.7 & .000 \\
\hline 5 & Constipation & .562 & 56.2 & .000 \\
\hline 6 & Nausea-vomiting & .734 & 73.4 & .000 \\
\hline 7 & Menstrual changes & .118 & 11.8 & .018 \\
\hline 8 & Health status & .001 & - & .833 \\
\hline 9 & $\begin{array}{l}\text { Fatigue, pain, and sleep disturbance (normally distributed } \\
\text { data) }\end{array}$ & .880 & 88.0 & .000 \\
\hline 10 & $\begin{array}{l}\text { Appetite changes, constipation, nausea-vomiting, menstrual } \\
\text { changes, and health status (abnormally distributed data) }\end{array}$ & .966 & 96.6 & .000 \\
\hline
\end{tabular}

Table 4b: Predictors of physical wellbeing in BCS

\begin{tabular}{|c|c|c|c|c|}
\hline No. & Determinant & R Square & $\%$ OF Influence & Sig. \\
\hline 1 & Fatigue & .599 & 59.9 & .000 \\
\hline 2 & Appetite changes & .757 & 75.7 & .000 \\
\hline 3 & Pain & .480 & 48.0 & .000 \\
\hline 4 & Sleep disturbance & .348 & 34.8 & .000 \\
\hline 5 & Constipation & .531 & 53.1 & .000 \\
\hline 6 & Nausea-vomiting & .551 & 55.1 & .000 \\
\hline 7 & Menstrual changes & .252 & 25.2 & .000 \\
\hline 8 & Health status & .099 & 9.9 & .016 \\
\hline 9 & $\begin{array}{l}\text { Fatigue, pain, and sleep disturbance (normally distributed } \\
\text { data) }\end{array}$ & .809 & 80.9 & .000 \\
\hline 10 & $\begin{array}{l}\text { Appetite changes, constipation, nausea-vomiting, } \\
\text { menstrual changes, and health status (abnormally } \\
\text { distributed data) }\end{array}$ & .904 & 90.4 & .000 \\
\hline
\end{tabular}


Disease stressor and cancer therapy cause the decrease of four main body functions (cognitive, nutrition, muscular tone, and sleep quality) influencing the adjustment to sick condition, in which the changes of biological, psychological, and functional aspects induce CRF in cancer survivors (8). This statement was confirmed by a study of Bower, et al. (2011) which found that women treated with chemotherapy endorsed higher levels of all symptoms and also had higher plasma levels of soluble Tumor Necrosis Factor Receptor type II (sTNF-RII) than women who did not receive chemotherapy (all $p<.05$ ). Fatigue was positively associated with sTNF-RII, particularly in the chemotherapy-treated group $(p<.05)(9)$.

Pain in cancer patients remains common and is often associated with insufficient prescription of targeted analgesia in which the proportion of pain caused by cancer treatment was higher in neuropathic pain compared to all types of cancer pain (10). Pain was found to be significantly different in CCS and BCS. Table 3 showed that most CCS experienced moderate pain (55.32\%), compared to mostly mild pain in BCS (65.52\%). This possibly happened due to insufficient analgesia or the complexity of cancer treatment followed by CCS as shown in Table 2. Other than that, advanced cervical cancer could cause symptoms including abnormal vaginal bleeding, also after coitus, discharge, pelvic pain, and dyspareunia (pain during intercourse) (11).

Sleep disturbance is one of the risk factor of cancer because melatonin (pineal hormone) is involved in the inhibition of cancer development and growth, and the enhancement of immune function. Individuals with sleep disturbances are not only immuno- suppressed, but they are also at an increased risk of developing a number of different types of cancer (12). Sleep disturbance are common adverse effects of cancer treatment (10). Sleep disturbance was found to be significantly different in CCS and BCS, in which it is being the best predictor of physical wellbeing in CCS $(84.7 \%$ of influence). Table 3 showed that most CCS experienced moderate sleep disturbance $(40.43 \%)$, compared to mostly mild sleep disturbance in BCS (67.24\%). This possibly happened due to the adverse effects of cancer treatment, in which CCS undertook more complicated treatment than BCS as shown in Table 2. Sleep disruption is prevalent in patients with cancer and survivors, in which insomnia due to depression is prevalent, under-recognized, undermanaged, and understudied among patients with cancer, especially in those receiving chemotherapy (13). So, other than therapy, psychological distress in term of depression potentially causes sleep disturbance generally in people living with cancer.

Appetite changes in cancer survivors happen due to taste and smell changes related to side effects of chemotherapy and socio-demographic factors, such as women in younger age, previous smell changes, less responsibility for cooking, concurrent medication, higher educational levels, and being on sick leave (14). Loss of olfactory/gustatory function can lead to malnutrition, weight loss, and possibly a prolonged morbidity of chemotherapy-induced adverse effects, decreased quality of life, poor compliance, and even decreased therapy response (15). Appetite change was found to be significantly different in CCS and BCS, in which it is being the best predictor of physical wellbeing in BCS (75.7\% of influence). Table 3 showed that most CCS experienced severe appetite changes (38.30\%) compared to mostly mild appetite changes in BCS (70.69\%). This possibly happened due to the adverse effects of chemotherapy. From table 2 we could see that $87.23 \%$ CCS undertook chemotherapy as one of their main regiment, compared to $44.83 \%$ in BCS (totally). Chemotherapy has a significant but transient effect on olfactory and gustatory function, possibly causing reduced appetite, a low energy intake, and weight loss in breast cancer and other gynecologic malignancies in women (15).

Constipation is a significant problem in patients taking morphine for alleviating cancer pain which affects a large proportion of cancer patients taking oral morphine, and this problem is generally inadequately treated (16). Table 3 showed that in both cases mild constipation occurred in most cases, but we could find more moderate and severe constipation in CCS even when more BCS participated in this study. This possibly happened due to the side effects of analgesic consumption, especially oral morphine or opioid. Constipation affects many patients receiving long-term opioid therapy for managing cancer pain (17). The data of opioid consumption in study respondents was not collected, but there were $6.67 \%$ respondents reported oral medicine consumption (unspecified).

Nausea is a subjective phenomenon of an unpleasant, wavelike sensation experienced in the back of the throat and/or the epigastrium often culminating in vomiting (emesis). Vomiting is the forceful expulsion of the contents of the stomach, duodenum, or jejunum through the oral cavity. Vomiting can serve the function of emptying noxious chemicals from the gut, and nausea appears to play a role in a conditioned response to avoid ingestion of offending substances (18). Table 3 showed that mild nausea-vomiting occurred mostly in both cases, but we could find more moderate and severe nausea-vomiting in CCS. This possibly happened due to the side effects of chemotherapy. Nausea and vomiting are two of the most frequent and troubling side effects patients experience during chemotherapy, interfering with compliance with cancer therapies and quality of life (19). From table 2 we could see that $87.23 \%$ CCS undertook 
chemotherapy as one of their main regiments, compared to $44.83 \%$ in BCS (totally). There are many factors inducing nausea-vomiting in cancer patients receiving opioids, such as age, body mass index, Karnofsky Performance Status, gender, usage of antiemetics, type of opioid, type of cancer and eight types of single nucleotide polymorphism (SNP) (20). The data of opioid consumption in study respondents was not collected, but there were $6.67 \%$ respondents reported oral medicine consumption (unspecified).

The diagnosis of cancer appears to highlight concerns regarding menstrual changes and potential infertility, especially in younger women with breast cancer (21). Table 3 showed that most CCS experienced moderate menstrual changes $(51.06 \%)$, compared to most mild menstrual changes in BCS (53.45\%). This possibly happened due to the side effects of chemotherapy. From table 2 we could see that $87.23 \%$ CCS undertook chemotherapy as one of their main regiment, compared to $44.83 \%$ in BCS (totally). History of hysterectomy was also important in determining menstrual changes in CCS, but this variable was unidentified in this study.

Laparoscopic surgical techniques, including fertilitysparing radical hysterectomy, have been proven to improve the quality of life in CCS (22). Premenopausal women undergoing chemotherapy are at risk for amenorrhea and impaired fertility. In young women with breast cancer, chemotherapy decreases mullerian inhibitory substance rapidly and dramatically. Ovarian reservation and endocrine function may be affected differently by chemotherapy among different patients (23). Similar study in CCS is not yet been demonstrated. Despite more serious cancer symptoms (especially pain and fatigue) occurred in CCS as shown in Table 3, more BCS perceived poor health status. Perceived health status in cancer patient is influenced by education level, economic status, type of social insurance, time of cancer diagnosis, status of cancer, metastasis (24). Health status, especially in BCS, is also associated with occupation, pain, and fatigue (25). From Table 1 we could see that generally BCS were better educated than CCS, but they had similar economic status which was probably because most of them were housewives so that they could not contribute to the family's income. Health status could improve over time along with the disease progression, in which survival time was independently associated with health status and quality of life in cancer survivors (26). Most respondents had survived from cancers for more than four years, as shown in Table 2 that most respondents were firstly diagnosed with cancer before 2014.

Overall physical wellbeing was better in BCS, but most respondents reported sufficient wellbeing in both cases. Fatigue, appetite changes, pain, sleep disturbance, constipation, nausea-vomiting, menstrual changes, and health status (perceived) contribute to cancer survivors' physical wellbeing in such a way so that it could be found better in BCS mostly due to relative absence of chemotherapy side effects because most respondents undertook surgery as their main regiment. Therefore early detection of cervical cancer should be promoted to younger women so that surgery could be performed as early as possible to avoid the various side effects of chemotherapy in the case of advanced stage cervical cancer.

\section{CONCLUSION}

More severe cancer symptoms were found in CCS, but poorer perceived health status was found in BCS. There were significant differences of fatigue, pain, sleep disturbance, appetite changes, constipation, nauseavomiting, menstrual changes, and perceived health status found between CCS and BCS. Sleep disturbance and appetite changes are the best predictor of physical wellbeing in CCS and BCS respectively. Overall, physical wellbeing was significantly different between CCS and BCS.

\section{ACKNOWLEDGEMENTS}

This study was funded by the Center of Food and Nutritional Research, Institute of Research and Community Service, Widya Mandala Catholic University Surabaya, by Grant number: 077a/WM01.5.2/N/2018. This publication was supported by Faculty of Nursing, Widya Mandala Catholic University Surabaya.

\section{DECLARATIONS}

\section{Ethics approval and consent to participate}

This study protocol has been reviewed for ethical purposes. Ethical clearance was issued by Faculty of Nursing, Universitas Airlangga, Surabaya, Indonesia, with certificate number of 681-KEPK. Prior to data collection, all respondents got explanation about study benefits and potential risk, and other technical instructions. All respondents had signed the consent forms and expressed the agreement to participate in this study.

\section{Competing interest}

I declare that I do not have any competing interest, especially with the study funder.

\section{REFERENCES}

1. Jong W. Cancer: What is It? Therapy, Hope, Life, and Family Support (in Bahasa Indonesia). 2005. Jakarta: Arcan.

2. Tejawinata S. Surabaya, The City of Palliative: Its Image and Charm (in Bahasa Indonesia). 2012. Surabaya: Airlangga University Press. World Health Organization 
(WHO). Cancer Country Profiles (2014). 2015. Retrieved from: https://www.who.int/cancer/country-profiles/en/

3. Macleod R. Total pain - physical, psychological and spiritual. Handout of Goodfellow Symposium 2007. $2007 . \quad$ Retrieved from: https://www.fmhs.auckland.ac.nz/assets/fmhs/soph/go odfellow/docs/total_pain_handout.pdf

4. Cole P. Early Childhood Briefing Paper Series All Children Ready for School: Health and Physical Well-Being. 2006. Retrieved from: https://www.iidc.indiana.edu/styles/iidc/defiles/ecc/sru d-health.pdf

5. Ferrel BR, Hassey-Dow K, Grant M. Measurement of the quality of life in cancer survivors. Quality of Life Research. 1995; 4: 523-531.

6. Ferreira KASL, Kimura M, Teixeira MJ, Mendoza TR, Nobrega JCM, Graziani SR, Takagaki TY. Impact of cancer-related symptom synergisms on health-related quality of life and performance status. J Pain Symptom Manage. 2008; 35(6): 604-616.

7. Jean-Pierre P, Figueroa-Moseley CD, Kohli S, Fiscella K, Palesh OG, Morrow GR. Assessment of cancer-related fatigue: implications for clinical diagnosis and treatment. The Oncologist. 2007; 12 (suppl. 1): 11-21.

8. Mitchell S. Cancer-related fatigue: state of the science. Am Acad Phys Med Rehabil R. 2010; 5: 609-617.

9. Bower JE, Ganz PA, Irwin MR, Kwan L, Breen EC, Cole SW. Inflammation and behavioral symptoms after breast cancer treatment: do fatigue, depression, and sleep disturbance share a common underlying mechanism?. J Clin Oncol. 2011; 29(26): 3517-3522.

10. Bennett MI, Rayment C, Hjermstad M, Aass N, Caraceni A, Kaasa S. Prevalence and aetiology of neuropathic pain in cancer patients: a systematic review. PAIN. 2012; 153(2): 359-365.

11. Colombo N, Carinelli S, Colombo A, Marini C, Rollo D, Sessa $C$, on behalf of the ESMO Guidelines Working Group. Cervical cancer: ESMO clinical practice guidelines for diagnosis, treatment and follow-up. Annals of Oncology. 2012; 23 (Supplement 7): vii27-vii32.

12. Blask DE. Melatonin, sleep disturbance and cancer risk. Sleep Medicine Reviews. 2009; 13(4): 257-264.

13. Palesh OG, Roscoe JA, Mustian KM, Roth T, Savard J, Ancoli-Israel S, Heckler C, Purnell JQ, Janelsins MC, Morrow GR. Prevalence, demographics, and psychological associations of sleep disruption in patients with cancer: University of Rochester Cancer CenterCommunity Clinical Oncology Program. J Clin Oncol. 2010; 28(2): 292-298.

14. Bernhardson BM, Tishelman C, Rutqvist LE. Self-reported taste and smell changes during cancer chemotherapy. Supportive Care in Cancer. 2008; 16(3): 275-283.

15. Steinbach $S$, Hummel T, Bohner $C$, Berktold $S$, Hundt W, Kriner M, Heinrich P, Sommer $H$, Hanusch C, Prechtl A,
Schmidt B, Bauerfeind I, Seck K, Jacobs VR, Schmalfeldt $B$, Harbeck N. Qualitative and quantitative assessment of taste and smell changes in patients undergoing chemotherapy for breast cancer or gynecologic malignancies. J Clin Oncol. 2009; 27(11): 1899-1905.

16. Droney J, Ross J, Gretton S, Welsh K, Sato H, Riley J. Constipation in cancer patients on morphine. Supportive Care in Cancer. 2008; 16(5): 453-459.

17. Dhingra L, Shuk E, Grossman B, Strada A, Wald E, Portenoy A, Knotkova H, Portenoy R. A qualitative study to explore psychological distress and illness burden associated with opioid-induced constipation in cancer patients with advanced disease. Palliative Medicine. 2012; 27(5): 447-456.

18. Kumar NB. Nausea and vomiting in cancer. Nutritional Management of Cancer Treatment Effects. 2012; 107130.

19. Janelsins MC, Tejani MA, Kamen C, Peoples AR, Mustian KM, Morrow GR. Current pharmacotherapy for chemotherapy-induced nausea and vomiting in cancer patients. Expert Opinion on Pharmacotherapy. 2013; 14(6): 757-766.

20. Laugsand EA, Fladvad T, Skorpen F, Maltoni M, Kaasa S, Fayers $P$, Klepstad $P$. Clinical and genetic factors associated with nausea and vomiting in cancer patients receiving opioids. Eur J Cancer. 2011; 47(11): 1682-1691.

21. Peate $M$, Meiser B, Hickey $M$, Friedlander $M$. The fertility-related concerns, needs and preferences of younger women with breast cancer: a systematic review. Breast Cancer Res Treat. 2009; 116: 215.

22. Eifel PJ, Levenback C. Cervical cancer. 60 Years of Survival Outcomes at The University of Texas MD Anderson Cancer Center. 2012. pp. 97-107.

23. Yu B, Douglas N, Ferin MJ, Crew K, Lobo RA, Hershman $D L$. Changes in markers of ovarian reserve and endocrine function in young women with breast cancer undergoing adjuvant chemotherapy. Cancer. 2010; 116(9): 20992105.

24. Park JS, Oh YJ. An analysis of cancer symptoms, perceived health status, and given nursing services for community dwelling cancer patients who are registered in a public health center. J Korean Oncol Nurs. 2010; 10(1): 48-58.

25. Tae YS, Kim MY. Relationships between family support, perceived health status, and self-esteem in Korean women with breast cancer. J Korean Oncol Nurs. 2011; 11(1): 41-48.

26. Thong MSY, Mols F, Coebergh JWW, Roukema JA, van de Poll-Franse LV. The impact of disease progression on perceived health status and quality of life of long-term cancer survivors. Journal of Cancer Survivorship. 2009; 3(3): 164-173. 